\title{
Paracetamol is not superior to placebo for acute low back pain
}

Paracetamol is no more effective than placebo for the treatment of acute low back pain, according to the results of a randomized controlled trial published in The

Lancet. In terms of median time to recovery from pain, patients who took paracetamol-either regularly or according to need-were found to be indistinguishable from those who received placebo.

Low back pain is a highly prevalent and debilitating condition that imposes a substantial economic and societal burden worldwide. "While guidelines recommend regular paracetamol as the first-choice analgesic for low back pain, this is actually only based on indirect evidence; that is, in patients with low back pain, paracetamol has only been compared with other medications," explains Christopher Williams, the lead author of the new study.

The researchers recruited 1,643 patients with acute low back pain from 235 primary care centres in Sydney, Australia. The participants were randomly allocated to regular paracetamol treatment $(n=550)$, paracetamol as needed $(n=546)$, or placebo $(n=547)$.

"To ensure adequate blinding, we used a double-dummy placebocontrolled design, which means that every patient had one type of tablet to take regularly and one type to take as needed for pain relief," says Williams. "In one group, the regular tablets contained real paracetamol and the as-needed tablets were placebo; in the next group, the as-needed table contained real paracetamol and the regular tablets were placebo; and in the third group, both sets of tablets were placebo."
In both the regular and as-needed paracetamol groups, median time to recovery from pain was 17 days, compared with 16 days in the placebo group. Secondary outcomes, including adverse event profiles, adherence to treatment and quality of life, were also comparable between the three groups during the 3-month follow-up period.

"This tells us two things," suggests Williams. "First, in addition to good advice and reassurance from a doctor, pain medications don't seem to have much benefit. Second, as paracetamol works to relieve pain for a range of conditions, such as headache, toothache and pain straight after surgery, the mechanisms of back pain are likely to be different from other pain conditions, and this is an area that we need to study more."

On the basis of these results, the authors propose that the current recommendation of paracetamol as a first-line treatment for acute low back pain warrants reconsideration. They also advocate further exploration of nonpharmacological strategies, such as providing reassurance to patients regarding their prospects of recovery, and encouraging them to avoid bed rest and remain active.

\section{Heather Wood}

Original article Williams, C. M. et al. Efficacy of paracetamol for acute low-back pain: a doubleblind, randomised controlled trial. Lancet doi:10.1016/S0140-6736(14)60805-9

Further reading Koes, B. W. et al. An updated overview of clinical guidelines for the management of non-specific low back pain in primary care. Eur. Spine J. 19, 2075-2094 (2010)

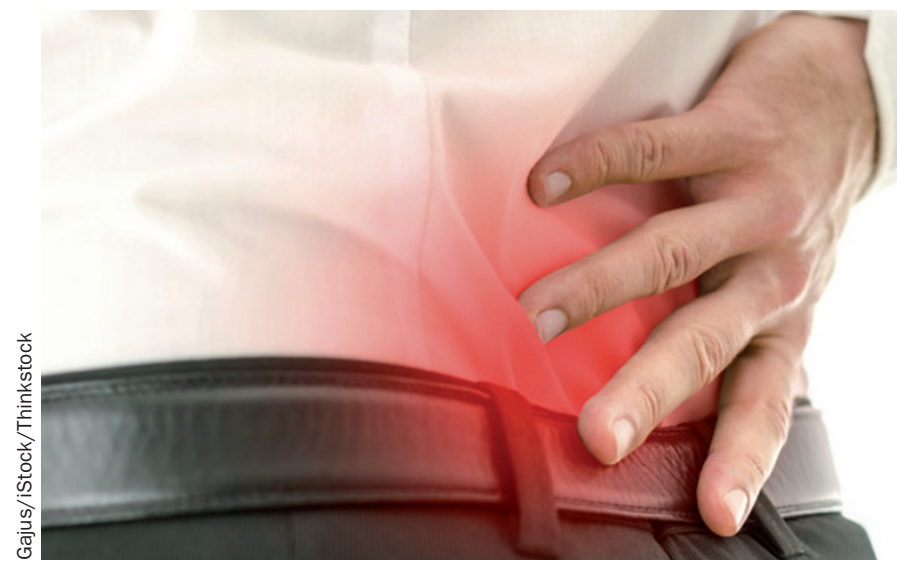

